\title{
Incidencia judicial práctica de la modificación operada por la Ley 18/2009, de 23 de noviembre por la que se modifica el texto articulado de la Ley sobre tráfico, circulación de vehículos a motor y seguridad vial, en materia sancionadora
}

\author{
Miriam Rodríguez Natal, Elena Veleiro Couto, José Balbuena Jiménez \\ y Juan Romero Sánchez \\ Abogados del Estado ante los Juzgados de lo contencioso-administrativo de Madrid \\ ju.romero@dsje.mju.es
}

\begin{abstract}
Resumen
La Ley 18/2009, de 23 de noviembre aborda modificaciones en la configuración del sistema de responsabilidad en los supuestos en que la identificación de un hecho por parte de un conductor infractor no puede producirse en el acto de la comisión, medida por la que se introduce un nuevo concepto, el de "conductor habitual", que es la persona que está inscrita en el Registro de Conductores Infractores. Por otro lado, esta misma Ley modifica las consecuencias sancionadoras de los hechos infractores elevando cuantitativamente el pago de las multas muy graves a la cuantía de 500 euros.

El objetivo principal de este artículo es mostrar al lector las consecuencias de la modificación de la Ley 18/2009, de 23 de noviembre, reforma legislativa por la que aumentan notablemente los deberes de colaboración a cargo del titular del vehículo.
\end{abstract}

Palabras clave Tráfico; Seguridad vial; Transportes. Vehículos. Sanciones administrativas; Legislación; Reforma legislativa; España; 2009.

\section{Judicial practical incident of the modification produced by the law $18 / 2009$, of 23 november by the articulated text of the law is modified on traffic, traffic of engine vehicles and road safety, in sanction subject}

\footnotetext{
Abstract

The Law 18/2009, of November 23 presents modifications in the configuration of the system of responsibility in the suppositions in which the identification of an offender driver, this traffic fact cannot be identified forthwith at place, it is the cause of a new concept, the "habitual driver", who is the person that has been inscribed in the Register of Offenders Drivers. On the other hand, the same Law modifies the sanctions consequences it increase the payment of the serious fines to the quantity of 500 Euros.

The article shows to the reader the consequences of the modification of the Law 18/2009, of November 23: the collaboration is high notably at the expense of the owner of the vehicle in traffic sanctions subject.
} 


\section{INTRODUCCIÓN}

La modificación del RD Legislativo 339/1990, de 2 marzo, por el que se aprueba el Texto Articulado de la Ley sobre Tráfico, Circulación de Vehículos a Motor y Seguridad Vial, llevada a efecto la Ley 18/2009, de 23 de noviembre, viene a llevar a cabo una reforma integral del procedimiento sancionador, con el fin de adaptarlo a la reciente realidad en la materia. consecuencia de la experiencia adquirida durante los últimos años por los órganos administrativos.

No obstante, ha de tenerse en cuenta que, dada la reciente entrada en vigor de la misma, la efectiva aplicación de la nueva normativa no ha tenido todavía el suficiente asentamiento judicial como para poder sistematizar con el detalle necesario la incidencia que la misma tiene, o tendrá, en sede judicial.

Sin embargo, a pesar de la todavía corta vigencia de las modificaciones introducidas, existen no obstante ciertos aspectos puntuales que ya se han hecho notar a día de hoy en la práctica procesal ordinaria.

Es por ello que se ha estimado oportuno abordar este breve análisis procediendo, en primer lugar, a sistematizar las principales innovaciones introducidas por la Ley; y a continuación, a atender a concretos aspectos de la misma que han tenido cierta, aunque todavía tímida, repercusión judicial.

En este sentido procederemos a ahora analizar ambos aspectos.

\section{PRINCIPALES MODIFICACIONES EN MATERIA SANCIONADORA INTRODUCIDAS POR LA MODIFICACIÓN OPERADA POR LA LEY 18/2009, DE 23 DE NOVIEMBRE}

En un intento de seguir profundizando en el camino emprendido con la entrada en vigor del permiso y licencia de conducción por puntos el 1 de enero de 2006, en orden a la reducción de la mortalidad en nuestras carreteras, la Ley 18/2009 pretende dar respuesta a las críticas vertidas a uno de los aspectos fundamentales de la nueva regulación en materia de trafico cual es el aspecto previo a la retirada de los puntos, esto es el procedimiento sancionador.

Así, constituyendo éste el eje principal de la reforma dando una nueva redacción por tanto a los títulos V y VI, la Ley $18 / 2009$ ha modificado otros títulos, unos derivados de la propia modificación del procedimiento sancionador y otros como consecuencia de la necesidad de dar una nueva redacción a otras materias de la propia Ley de Trafico. A continuación trataremos de sintetizar las principales modificaciones operadas tanto en el procedimiento sancionador como en los 
1. Se da una nueva ordenación del ahora llamado "Consejo Superior de Seguridad Vial”, antes “Consejo Superior de Trafico y Seguridad de la Circulación Vial” (artículo 8 de la Ley de Trafico). En este sentido, se define expresamente como "el órgano de consulta y participación para el desarrollo y ejecución de la política de seguridad vial". Se contempla un catalogo de funciones propias del citado Consejo. En la estructura del mismo merecen especial atención, la introducción de la Comisión Permanente, la Comisión autonómica y la Comisión Local de Seguridad Vial, recogiendo así expresamente en su estructura la que con anterioridad contemplaba el articulo 8.5 de la Ley de Trafico al disponer que " Se constituirá una Comisión del Consejo en cada Comunidad Autónoma".

De igual forma, se introduce ahora la posibilidad de crear en cada Comunidad Autónoma con competencia ejecutiva en materia de tráfico y Seguridad Vial Consejos de Seguridad Vial, e igualmente se prevé la creación de Consejos Territoriales de Seguridad Vial.

2. Con la modificación del artículo 9 de la Ley de Tráfico e introducción de un nuevo artículo 9 bis se establecen un catálogo de Obligaciones generales dirigidas tanto al Titular del vehículo como a los arrendatarios y conductores, mientras que el artículo 9.bis se refiere a las obligaciones específicas del titular del vehículo, entre las que se contempla el deber de identificación del conductor infractor (antes recogido en el artículo 72.3), si bien quedará exonerado de sus obligaciones el titular que comunique al Registro de Vehículos de la DGT el conductor habitual del mismo (apartado que no entrará en vigor hasta el 25 de noviembre de 2010). Igualmente, destaca la obligación de no distracción que se impone al conductor en la línea de la idea de seguridad preventiva en la conducción que persigue la ley de tráfico tras la reforma como medio más eficaz en la evitación de accidentes en la carretera.

3. Otra importante novedad de la Ley 18/2009 es la inclusión de la "Dirección Electrónica Vial” (DEV) que coexiste con el tradicional domicilio físico, al objeto de evitar los problemas de desconocimiento de la existencia de procedimientos sancionadores así como de recibir información de todo tipo referente a tráfico como la necesidad de someter al vehículo a la inspección técnica periódica (Artículo 59 bis). Esta DEV será obligatoria para las personas jurídicas y voluntaria para las personas físicas.

4. Se crea el Registro Estatal de Víctimas y Accidentes de Tráfico y se contempla la posibilidad de que cada Comunidad Autónoma cree su registro propio, con la finalidad de obtener la información necesaria para determinar las causas y circunstancias en que se producen los accidentes de tráfico y sus consecuencias (Título VI de la Ley).

5. En materia sancionadora podemos destacar en primer lugar la inclusión como infracciones muy graves algunas que con anterioridad eran graves, como la tipificación como muy grave la utilización de mecanismos destinados a eludir la vigilancia y control del tráfico. 
Especial importancia revisten las infracciones consistentes en excesos de velocidad que han pasado de graduarse mediante porcentajes a un sistema de fijación de la cuantía de la multa en una cantidad exacta, modificable únicamente por circunstancias adicionales concurrentes, como los antecedentes del infractor o el peligro potencial creado, consiguiéndose así que el infractor tenga la certeza de las consecuencias de su comportamiento infractor con independencia de la Administración que ejerza la competencia sancionadora.

En relación a las sanciones, la reforma opera también en el catálogo de sanciones existentes. Así, se deroga la sanción consistente en la imposibilidad de obtener el permiso por el período de dos años tras haber sido denunciado, hoy condenado, por conducir careciendo de permiso y se suprime la sanción de suspensión de la autorización administrativa para conducir.

Se atiende a la problemática de los conductores no residentes que infringen en nuestro país, en cuyo caso, el Agente denunciante fijará la cuantía de la multa y, de no depositarse su importe, el conductor deberá trasladar el vehículo e inmovilizarlo en el lugar indicado por el Agente denunciante, teniendo presente en cuanto al depósito la aplicación de la reducción del 50 por 100 de la multa inicialmente fijada de acuerdo con lo dispuesto en el artículo 80 de la Ley de tráfico.

6. Pasando al estudio del procedimiento sancionador, materia que constituye eje central de la reforma practicada por la Ley 18/2009, debe señalarse que la idea esencial sobre la que gira la modificación legislativa es la creación de un procedimiento sancionador específico en materia de tráfico a semejanza de los procedimientos administrativos especiales que existen en materia de infracciones y sanciones en el orden social, así como con respecto a las infracciones tributarias.

Muestra fundamental de esta intención del legislador es el hecho de que la Ley 18/2009 realiza una modificación de la "norma fundamental" de los procedimientos administrativos, es decir, la conocida Ley 30/1992, de 26 de noviembre, de Régimen Jurídico de las Administraciones Públicas y del Procedimiento Administrativo Común; en concreto, se incorpora a la citada norma una Disposición Adicional Octava Bis, con el fin de alterar el orden de prelación de las fuentes que rigen las infracciones y sanciones administrativas en materia de tráfico, de manera que las mismas se regirán en primer lugar por su normativa específica, el Texto Articulado de la Ley sobre el Tráfico, Circulación de Vehículos a Motor y Seguridad Vial y las disposiciones reglamentarias que lo desarrollen, y de manera supletoria por la Ley 30/1992. Se establece, por lo tanto, un régimen jurídico idéntico al que las Disposiciones Adicionales Quinta y Sexta de la Ley 30/1992 prescriben para las infracciones sociales y las tributarias.

7. Dentro de esta idea esencial del procedimiento sancionador específico en materia de tráfico, uno de los aspectos más novedosos y de los más conocidos por los destinatarios de la norma es el establecimiento de un nuevo procedimiento abrevia326 do, que permite reducir en gran medida el plazo de resolución de los expedientes 
sancionadores. En efecto, entre las críticas que recaían sobre el iter procedimental tras la introducción del carnet por puntos, destacaba la excesiva dilación del mismo, la cual provocaba situaciones tan paradójicas como el hecho de que, mientras las infracciones por conducir bajo la influencia de bebidas alcohólicas tipificadas, por su especial gravedad, como delito recibían una respuesta sancionadora inmediata a través de los denominados "juicios rápidos" de la jurisdicción penal, las mismas transgresiones de la norma que no excedían los límites de la infracción administrativa veían demorada la firmeza de la sanción y la detracción de los puntos durante varios meses.

El procedimiento abreviado tiene lugar cuando se produce el pago voluntario de la sanción, bien en el momento de la entrega de la denuncia, o bien dentro del plazo de quince días naturales contados desde el día siguiente de la notificación. La consecuencia esencial es que la cuantía de la sanción se reduce al 50\% de su importe; el procedimiento queda finalizado en la vía administrativa sin necesidad de que se dicte resolución expresa desde el día que se produce el pago, renunciándose a la posibilidad de discutir la comisión de la infracción en la vía administrativa, siendo la sanción únicamente discutible ante el orden jurisdiccional contencioso-administrativo.

Este procedimiento no podrá ser aplicado en los casos en los que la infracción consista en conducir vehículos que tengan instalados inhibidores de radar o cualesquiera otros mecanismos encaminados a interferir en el correcto funcionamiento de los sistemas de vigilancia de tráfico o en el incumplimiento por el titular o el arrendatario del vehículo con el que se haya cometido la infracción de identificar al conductor del mismo de manera veraz. Tampoco es aplicable en los casos de las infracciones tipificadas en el artículo 65.6 (relativas al régimen de autorización y funcionamiento de los centros de enseñanza y formación y de los centros de reconocimiento de conductores).

8. La segunda nota distintiva de la nueva norma es la relativa al nuevo régimen en la práctica de las notificaciones. Como ya se ha señalado en el apartado tercero de esta exposición, la norma ha creado el concepto de Dirección Electrónica Vial (DEV) y el Tablón Edictal de Sanciones de Tráfico en formato digital.

De acuerdo con la nueva regulación la notificación de las denuncias (y de las restantes resoluciones) que no sean entregadas en el acto tendrá lugar en la DEV (en este caso se practicará 1 solo intento) o cuando la misma no exista en el domicilio que expresamente se hubiese indicado para el procedimiento (notificación por correo postal de la que se practican 2 intentos) o bien en el que figure en los Registro de la Dirección General de Tráfico.

Cuando las indicadas notificaciones producen un resultado infructuoso se acude al mencionado Tablón Edictal de Sanciones de Tráfico, que es una web certificada, que evita acudir a la publicación en los Boletines Oficiales, los cuales si bien proporcionaban garantías formales de la comunicación de las resoluciones al in- 
fractor en la práctica implicaban un cierto grado de inseguridad para el conductor al no existir garantía material del conocimiento del procedimiento por parte del interesado.

9. Otra de las nuevas aportaciones de la Ley, tendente también a la reducción de la duración actuación administrativa, es la terminación de oficio del procedimiento sancionador en los casos de falta de actuación por parte del conductor, atribuyéndole importantes consecuencias a su inactividad.

En los casos en los que el conductor infractor no formula alegaciones ni abona el importe de la multa en el plazo de los quince días naturales posteriores a la notificación de la denuncia ésta adquiere carácter de acto resolutorio, lo que implica la finalización del procedimiento y la posibilidad de proceder a la ejecución de la sanción en el plazo de los treinta días naturales posteriores a la notificación de la denuncia.

10. Otra cambio normativo esencial es la eliminación del recurso de alzada al ser la resolución sancionadora un acto administrativo que agota la vía administrativa susceptible de impugnación directa ante la jurisdicción contencioso-administrativa.

Al desaparecer el recurso de alzada se establece una nueva regulación del recurso de reposición, el cual no suspende la ejecutividad del acto administrativo.

11. Las medidas cautelares sufren asimismo una importante revisión. En primer lugar varía su denominación que pasa a ser la de "medidas provisionales", al margen de este cambio nominativo, se producen otras modificaciones más esenciales como son la adopción de nuevas medidas y la redefinición de las ya existentes.

Las reformas se refieren a los siguientes aspectos:

- Se precisan los supuestos en los que se puede proceder a la inmovilización del vehículo.

— Junto a la retirada se regula el depósito de los vehículos.

- Se clarifican los supuestos en los que la Administración puede proceder a la destrucción del vehículo por producirse el abandono por parte del titular, medida que recibe la denominación de "tratamiento residual del vehículo".

- Por último, se contemplan otras medidas como las que tienen por objeto limitar al titular la disposición sobre sus autorizaciones administrativas cuando con las mismas quedasen sanciones firmes pendientes de abonar. Así, hay que destacar una novedad esencial, como es la nueva condición impuesta a los titulares de las autorizaciones administrativas de encontrarse al día del cumplimiento de las sanciones que se les impongan para poder efectuar cualquier trámite relativo a las mismas. 
12. En cuanto a la ejecución de las sanciones y la gestión de los antecedentes del infractor es importante destacar que la nueva Ley introduce varias medidas para aquellos infractores que no paguen al final del procedimiento sancionador destacando la regulación de la responsabilidad subsidiaria del titular del vehículo para aquellas multas que no sean pagadas por el conductor del mismo.

En relación con esta cuestión debe destacarse que el plazo de prescripción de las sanciones económicas y su cómputo se adaptan a los establecidos en la Ley 58/2003, de 17 de diciembre, General Tributaria, de modo que se amplía de 1 a 4 años el período de tiempo que tiene la Administración para exigir al infractor el pago de la multa no abonada.

Respecto a los plazos hay que mencionar que, sin embargo, se reduce el plazo de prescripción de las infracciones muy graves de 1 año a 6 meses que establece la nueva norma.

\section{INCIDENCIA PROCESAL DE CIERTAS MODIFICACIONES INTRODUCIDAS POR LA LEY 18/2009, DE 23 DE NOVIEMBRE}

Como ya expusimos al inicio de este artículo, se analizarán ahora aquellos concretos aspectos de la Ley 18/2009 que ya se han manifestado ante los tribunales de justicia.

Recordemos que, aún cuando la total y completa aplicación en sede judicial de las novedades introducidas por dicha Ley requerirá todavía que transcurra algún tiempo -habida cuenta de la normal demora en la aplicación de la nueva normativa a los expedientes administrativos sancionadores, conforme a la Disposición Transitoria Séptima de aquella Ley-, existen, no obstante, ciertos aspectos, que por su especial naturaleza o por el tratamiento que la misma Ley les atribuye, han requerido una aplicación casi inmediata y son objeto de enjuiciamiento ante esos tribunales de justicia.

Nos referiremos así a las tres cuestiones siguientes:

A) Entrada en funcionamiento del Centro de Tratamiento de Denuncias Automatizadas y la posible alteración de la competencia objetiva de los Juzgados de lo contencioso-administrativo: el Centro de Tratamiento de Denuncias Automatizadas fue objeto de creación a través de la Orden INT/2035/2007, de 2 de julio (BOE núm. 164, de 10 de julio de 2007), como órgano destinado a agilizar la tramitación de los procedimientos sancionadores por infracciones a las normas de circulación y seguridad cuya detección se produce mediante el empleo de medios técnicos de captación y reproducción de imágenes. 
Y conforme al artículo 2 de la precitada Orden, el mismo se integró en la estructura orgánica de la Subdirección General de Normativa y Recursos, de la Dirección General de Tráfico, de la cual depende funcional y orgánicamente, sin perjuicio de que se fijase su sede en la ciudad de León.

Del análisis de este precepto parece resultar que nos hallamos no ante un órgano periférico, sino central de la Administración General del Estado, con competencia en todo el territorio nacional. Y ello conllevaría una consecuencia fundamental en orden a una eventual impugnación ante la jurisdicción contencioso-administrativa.

En efecto, desde el punto de vista organizativo apuntado, entendemos que los expedientes sancionadores tramitados y resueltos por dicho órgano habrían de ser objeto de enjuiciamiento, no por los Juzgados de lo contencioso-administrativo sino por los Juzgados Centrales de lo contencioso-administrativo a esos Juzgados Centrales de lo contencioso-administrativo.

Y ello porque, al no poder calificar formalmente dicho Centro como periférico, una eventual impugnación jurisdiccional no tendría encaje en el supuesto del artículo 8.3 LJCA, sino en el artículo 9.b) LJCA, correspondiendo la competencia objetiva, como decimos, a esos Juzgados Centrales de lo contencioso-administrativo.

Sin embargo, lo cierto es que desde la puesta en funcionamiento de dicho Centro hasta la entrada en vigor de la Ley 18/2009 no tenemos constancia de que se plantease en la práctica dicha cuestión.

Con todo ello llegamos a la entrada en vigor de la Ley 18/2009, que entendemos vino a corregir legislativamente la disfuncionalidad apuntada.

Así, su artículo 7, relativo al Régimen sancionador, modifica el Título VII del Real Decreto Legislativo 339/1990, de 2 de marzo, por el que se aprueba el Texto Articulado de la Ley sobre Tráfico, Circulación de Vehículos a Motor y Seguridad Vial,

En particular, la reforma cambia la dicción literal del artículo 71, en los siguientes términos:

\section{Artículo 71. Competencias.}

1. La competencia para sancionar las infracciones a lo dispuesto en la presente Ley corresponde al Jefe de Tráfico de la provincia en que se haya cometido el hecho. Si se trata de infracciones cometidas en el territorio de más de una provincia, la competencia para su sanción corresponderá, en su caso, al Jefe de Tráfico de la provincia en que la infracción hubiera sido primeramente denunciada.

2. Los Jefes Provinciales podrán delegar esta competencia en la medida y extensión que estimen conveniente. En particular podrán delegar en el Director del 
yan sido detectadas a través de medios de captación y reproducción de imágenes que permitan la identificación del vehículo. Asimismo los órganos de las diferentes Administraciones Públicas podrán delegar el ejercicio de sus competencias sancionadoras mediante convenios o encomiendas de gestión o a través de cualesquiera otros instrumentos de colaboración previstos en la legislación de procedimiento administrativo común.

..."

Mediante este precepto se establece la posibilidad de que los Jefes Provinciales de Tráfico deleguen la competencia sancionadora en el Director del Centro de Tratamiento de Denuncias Automatizadas, cuando se refieran a infracciones que hayan sido detectadas a través de medios de captación y reproducción de imágenes. Y por tanto, se consagra normativamente aquella innovación competencial que planteó la Orden INT/2035/2007, por la que se creó dicho Centro.

Sin embargo, entendemos que tal forma de proceder (aún permitida por el artículo 13.1 LRJPAC, que no exige una relación jerárquica para llevar a efecto dicha delegación), resulta anómala si se atiende a la propia esencia de esta institución.

No se comprende, desde la configuración tradicional de la competencia y su forma de delegación, que a un órgano administrativo central se le deleguen las competencias que residen en los órganos periféricos. En efecto, aún cuando legalmente se prevé expresamente esta atribución, consideramos que desde un punto de vista de técnica administrativa, hubiese sido más procedente una avocación por parte del órgano administrativo central'1.

Cuestión que no es baladí a los efectos que nos interesan, pues al optar el legislador por la figura de la delegación, mantiene la procedencia de que las eventuales impugnaciones jurisdiccionales sean objeto de conocimiento por los Juzgados de lo contencioso-administrativo.

En efecto, si partimos del hecho incontestable de que, en caso de delegación, la resolución administrativa se entiende dictada por el órgano delegante -artículo 13.4 LRJPAC-, las resoluciones sancionadoras emanadas del Centro de Tratamiento de Denuncias Automatizadas han de entenderse dictadas por el Jefe Provincial de Tráfico correspondiente. Y por tanto, tras haber agotado el perceptivo recurso de alzada, su impugnación jurisdiccional sí tiene encaje en el señalado artículo 8.3 LJCA.

Ahora bien, residenciada formalmente la competencia en los Juzgados de lo contencioso-administrativo desde la modificación operada por la Ley 18/2009, ninguna discusión en definitiva cabe en orden a determinar el órgano jurisdiccional compe-

1 En este sentido se pronuncia también el Auto de 24 de septiembre de 2010, del Juzgado de lo contencioso-administrativo N.10 de Madrid, recaído en el Procedimiento Abreviado 458/2010. 
tente. Pero ello no impide que, desde un punto de vista puramente analítico o doctrinal, resulte criticable la forma de proceder del legislador, porque con dicha reforma ha validado legalmente una circunstancia anómala desde el punto de vista de organización administrativa y su consecuente impugnación judicial, esto es, que las resoluciones de un órgano central de la Administración General del Estado se enjuicien ante los Juzgados de lo contencioso-administrativo.

B) Aplicación retroactiva de la norma sancionadora más favorable: con evidente entronque en el artículo 9.3 CE y en el artículo 128.2 LRJPAC, y consagrado ya como postulado esencial en el ejercicio de toda potestad administrativa sancionadora ${ }^{2}$, la Disposición Transitoria.1 de la Ley 18/2009 no es ajena a dicha circunstancia y dispone:

"Los procedimientos sancionadores en tramitación a la entrada en vigor de esta Ley se seguirán rigiendo, hasta su terminación, por las normas vigentes en el momento de su iniciación, salvo que de acuerdo con lo previsto en la disposición final séptima pudieran derivarse efectos más favorables referentes a la suspensión del permiso de conducción y a la pérdida de puntos."

Y por su parte, esta Disposición Final Séptima señala:

"La presente Ley entrará en vigor a los seis meses de su publicación en el Boletín Oficial del Estado, salvo los artículos 9.bis 2, 59 bis, 77 y 78, que entrarán en vigor en el plazo de 1 año, y los efectos de esta Ley que sean favorables para el infractor, que entrarán en vigor el día siguiente al de su publicación en el Boletín Oficial del Estado."

Pues bien, del conjunto de ambas disposiciones queda conformado la aplicación retroactiva de la ley más favorable al infractor en el ámbito que nos ocupa³.

Y por tanto dicho régimen queda conformado de la siguiente manera:

- en el caso de la sanción accesoria de suspensión, la Disposición Transitoria.1 de la Ley 18/2009 es tajante a este respecto, permitiendo su aplicación sólo en los casos que la nueva normativa así lo prevea.

Recordemos en este sentido que dicha sanción accesoria -artículo 67 RD Legislativo 339/1990-, antes de la modificación operada, se aplicaba potestativamente, en el caso de infracciones graves, por el tiempo mínimo de un mes y máximo de hasta tres meses; y en el supuesto de infracciones muy graves, obligatoriamente, por los mismos períodos de tiempo mínimo.

STC 99/2000, de 10 de abril [RTC 2000/99]; y STS de 22 de febrero de 2005 [RJ 2005/5175].

Sentencia de 26 de julio de 2010, del Juzgado de lo contencioso-administrativo N.16 de Madrid, recaída en el Procedimiento Abreviado 722/2008.

Sentencia de 18 de enero de 2010, del Juzgado de lo contencioso-administrativo N.12 de Madrid, recaída en el Procedimiento Abreviado 379/2008. 
Sin embargo, tras la Ley 18/2009 dicha sanción adquiere un carácter muy excepcional, siendo aplicable sólo para la infracción prevista en el artículo 65.6.e) RD Legislativo 339/1990, en cuyo caso podrá aplicarse con una duración de hasta un año.

Por ello, salvo en los casos en que se sancione esa infracción (conducción temeraria), actualmente deberán quedar sin efecto las suspensiones que se hubiesen impuesto con arreglo a la normativa anterior.

- En el supuesto de la detracción de puntos, son aplicables las consideraciones anteriores. Nótese a este respecto la evidente mejora técnica que supone la a modificación operada a este respecto por la Ley 18/2009, pues si bien antes sólo se precisaba en el Anexo II las infracciones que llevaban aparejada la pérdida de puntos, actualmente se incorpora un nuevo Anexo IV donde se especifican concretamente los puntos a detraer por exceso de velocidad, en atención a la concreta velocidad captada por el cinemómetro.

Se incorpora así al texto legal este cuadro, que con anterioridad a la reforma se aplicaba a través de circulares internas remitidas por la Dirección General de Tráfico, con las consecuentes mayores garantías en la determinación de la concreta detracción a aplicar en cada caso.

En cualquier caso, de resultar menor la detracción de puntos conforme a la normativa actual es de obligado cumplimiento que se lleve a efecto la aplicación de esta última.

Circunstancia que se pondrá de manifiesto, sobre todo, en el caso de infracciones que antes llevasen aparejada esa pérdida de puntos y ahora no (o cuando los puntos a detraer ahora sean menos), pues la reforme operada reduce de 27 a 19 las infracciones que comportan esta sanción accesoria -Anexo II-.

Y por supuesto en el caso de infracciones por exceso de velocidad, cuando la aplicación del Anexo IV sea más favorable a la ponderación más flexible que en su día hiciese el órgano sancionador, conforme a los márgenes que determinaban las antedichas Circulares, de carácter meramente orientativo pero no vinculantes.

- Finalmente, en lo referente a la sanción pecuniaria, la Ley 18/2009 exceptúa expresamente la aplicación de esa norma sancionadora más favorable.

Ciertamente, a este respecto, hemos de señalar que, a excepción de casos concretos, se reducen las cuantías de la multa -artículo 67-, pues se pasa de un sistema de arco sancionador más elevado (hasta $90 €$ en las infracciones leves; de 91 a $300 €$ en las graves; y de 301 a $600 €$ en las muy graves) a un sistema de multa menor prácticamente no graduable (hasta $100 €$ en las leves, de $200 €$ en las graves, y de $500 €$ en las muy graves). 
Sin embargo, a pesar de esa considerable reducción, entendemos que no existe justificación para exceptuar el régimen de sanción pecuniaria a los postulados constitucionales, legales y jurisprudenciales más que consagrados en nuestro ordenamiento jurídico -artículos 9.3 y 25 CE, 2 CP, y 128 LRJPAC- que imponen como siempre necesaria la aplicación de la norma sancionadora más favorable al infractor.

Opción legislativa la de la reforma de la Ley 18/2009 que, por ello, entendemos más que criticable desde la perspectiva expuesta.

C) La identificación del conductor responsable de la infracción: La evolución jurisprudencial y doctrinal de la materia que nos ocupa parte del artículo 278 .II del derogado Código de Circulación aprobado por Decreto de 25 de septiembre de 1934 en el que la falta de identificación por el titular del vehículo, del conductor responsable de la infracción no se configuraba como una infracción autónoma. No es hasta la entrada en vigor del Texto Refundido de la Ley de Tráfico aprobado por el Real Decreto Legislativo 339/1990, de 2 de marzo, cuando la omisión de dicho deber se tipifica como infracción.

A diferencia del artículo 72.3 de la Ley de Tráfico, la redacción del artículo 278. Il acogía una forma de imputación de la denominada responsabilidad en cascada, al prever que, si el conductor responsable de la infracción no fuese conocido, el titular del vehículo, previo requerimiento de la Administración a facilitar los datos de dicho conductor, podría verse obligado al pago de la sanción pecuniaria que en su caso correspondiese a la infracción de tráfico cometida si dicha identificación no se lograse. Es decir se producía un desplazamiento de la responsabilidad, que para ser aceptable desde la óptica constitucional tiene que fundamentarse en la concurrencia de una circunstancia de carácter subjetivo exigible al sujeto que soporta dicho desplazamiento.

El Tribunal Constitucional consideró aceptable desde la óptica constitucional este desplazamiento de la responsabilidad al titular del vehículo por la infracción de tráfico, partiendo de la propia configuración del derecho de propiedad, al señalar " $E s$ indudable que el propietario de un vehículo en razón del conjunto de derechos y obligaciones dimanantes de sus facultades dominicales y esencialmente debido al riesgo potencial que la utilización de un automóvil entraña para la vida, salud e integridad de las personas, debe conocer en todo momento quién lo conduce. En caso contrario, esa falta de control sobre los bienes propios constituye un supuesto claro de culpa por falta de cuidado o vigilancia, cuya concurrencia posibilita de modo indubitado la traslación de la responsabilidad, que no podrá ser calificada en consecuencia de indebida ni de objetiva." (STC 154/1994, fundamento jurídico $3^{\circ}$ ).

Por su parte, el artículo 72.3 de la Ley de Tráfico, desarrollando la Base 8.6 de la Ley de Bases sobre Tráfico y Circulación de Vehículos a motor y Seguridad Vial, tipifica 334 por primera vez el incumplimiento del deber de comunicar la persona del conductor al establecer: "El titular del vehículo, debidamente requerido para ello, tiene el deber 
de identificar al conductor responsable de la infracción y si incumpliere esta obligación en el trámite procedimental oportuno sin causa justificada, será sancionado pecuniariamente como autor de falta grave".

Pese a la diferencia existente entre ambos preceptos, ya que el artículo 278.II determinaba al responsable frente al concepto de autoría introducido por el artículo 72.3, ambos presentaron como nexo común las dudas suscitadas sobre su constitucionalidad por vulneración del derecho a no declarar contra sí mismo y a no confesarse culpable.

En concreto, y por lo que se refiere a las cuestiones de inconstitucionalidad planteadas frente al artículo 72.3 de la Ley de Tráfico, los órganos judiciales proponentes, estimaban que la norma transcrita podría ser inconstitucional por vulnerar el derecho a no declara contra sí mismo, consagrado en el artículo 24.2 de la CE, en los supuestos en los que coincidiera en la misma persona la condición de titular del vehículo y de conductor que ha cometido la supuesta infracción de tráfico.

El Tribunal Constitucional aún señalando que la redacción del precepto no era técnicamente afortunada al referirse expresamente al deber del titular del vehículo “de identificar al conductor responsable de la infracción”, en primer lugar recordó que la declaración de responsabilidad o culpabilidad del conductor supuestamente autor de la infracción correspondía a la Administración como manifestación de su potestad sancionadora, previa tramitación del oportuno expediente sancionador con pleno respeto a las garantías constitucionales, en cuya tramitación el conductor podrá alegar en su descargo y proponer la práctica de cuantas pruebas fueran pertinentes o necesarias, pero en modo alguno dicha declaración le corresponde al titular del vehículo. De esta manera, no puede decirse que dicho precepto obligue a declarar a priori responsabilidades, ya que el titular del vehículo no es competente en modo alguno.

En segundo lugar, nuestro Alto Tribunal determinó "que el precepto cuestionado, configuraba un deber de colaboración del titular de un vehículo con la Administración, en el extremo exclusivamente referido, que resulta inherente al hecho de ser propietario" (STC 197/1995, de 21 de diciembre).

De esta manera, no cabe confundir el cumplimiento de una obligación legal pública de colaborar en la identificación del conductor presuntamente responsable de una infracción, con la obligación de "autoconfesar" conductas sancionables, ya que identificar al conductor, aun cuando fuere el propio titular requerido, no equivale a confesar la infracción. Obligar a la Administración a que realice una investigación más allá de lo racionalmente exigible para identificar al infractor, supondría desconocer el principio de colaboración del ciudadano con la Administración, y en la práctica resultaría la impunidad de muchas de las infracciones de tráfico, ante la imposibilidad real de concretar al infractor en el momento de la comisión, y el descargo del dueño de 
que no era él el conductor y que desconocía quien conducía en el tiempo en que se cometió la infracción.

La doctrina sentada por el Tribunal Constitucional determinó que tanto el artículo 278.II del Código de Circulación, como el artículo 72.3 de la Ley de Tráfico, no eran en sí mismos inconstitucionales, al resultar su dicción literal compatible con los postulados de la constitución. La vulneración de los derechos fundamentales en juego se produciría con una indebida interpretación y aplicación de la norma, ya que de una interpretación acorde a los postulados constitucionales no se puede inferir que de la notificación de la denuncia y de la advertencia de ser posible exigir la multa al titular del vehículo, resultara un legitimación a la autoridad sancionadora para imponer directamente la sanción pecuniaria, ni la exonera de proseguir las pertinentes diligencias de prueba, lo que determinaría un indebido traslado de responsabilidad personal a persona ajena al hecho infractor, a modo de una responsabilidad objetiva sin intermediación de dolo o culpa, sistema proscrito por la doctrina del TC Sentencia 76/1990, convirtiendo la comunicación de la denuncia y advertencia en una presunción iuris et de iure (Sentencias del Tribunal Constitucional 219/1988 de 22 de noviembre y 197/1995 de 21 de diciembre).

De esta manera, siempre que la administración asuma la carga de proseguir las pertinentes diligencias de prueba para conseguir la identificación del conductor, descarta la posibilidad de imputar automáticamente la responsabilidad de la infracción sin más al propietario, por el mero hecho de serlo lo que iría contra el principio de personalización de la sanción. Así, ante este deber de colaboración con la Administración en la investigación del ilícito administrativo no parece inconstitucional que se sancione pecuniariamente su infracción, pues, como se ha dicho por el Tribunal Constitucional (STC 103/1985) ante el deber de someterse al control de alcoholemia, no se obliga al interesado a emitir una declaración que exteriorice su contenido, admitiendo su culpabilidad; ni es inconstitucional el deber de aportar datos que puedan ayudar a la investigación practicada por la Inspección Tributaria al verificar la conducta fiscal del contribuyente (STC 110/1984).

Solucionadas las dudas planteadas sobre la constitucionalidad del precepto, otro de los problemas acaecidos es el relativo al modo en que ha de realizarse la identificación, ya que la normativa antes de la modificación llevada a cabo por Ley 18/2009, de 23 de noviembre no concreta las datos precisos a facilitar. En este sentido, la doctrina jurisprudencial sobre la materia entiende que es obvio que el titular del vehículo no sea hecho responsable del pago de la sanción simplemente porque la Administración no haya logrado identificar al conductor, dando lugar de esta manera a una responsabilidad objetiva, sin embargo es perfectamente compatible con el artículo 24.2 de la CE que la Administración pueda legítimamente valorar las respuestas evasivas o reticentes que no proporcionen los datos precisos para identificar al autor de la infracción o la simple negativa del titular. Recordemos que la Base 8.6 de la Ley 18/1989, de 25 de julio de Bases sobre Tráfico y Circulación de Vehículos a Motor y 336 Seguridad Vial ya señalaba un especial deber de diligencia del titular del vehículo que 
le obligaba a conocer y facilitar a la Administración “los datos necesarios" para identificar el conductor.

Por lo que a este aspecto se refiere, el Tribunal Constitucional en Sentencia 154/1994, de 23 de mayo declaró que "La presunción de inocencia ha quedado enervada por la conducta evasiva y reticente del actor ya que la ser preguntado por la Administración acerca de la identidad del conductor del vehículo, de un modo vago y genérico cita como posibles infractores a un albañil de entre los varios que pro aqueIlas fechas trabajaban en obra que estaba realizando en su casa, o también a cualquiera de sus tres hijos mayores que no conviven ya con el recurrente. En ninguno de los dos casos ofreció a la Administración las precisas señas de identidad que permitieran la localización de estas personas". "Tanto si el propietario ignora el oportuno requerimiento de identificación, como si lo atiende en forma inverosímil o incompleta, la administración podrá desde luego incoarle expediente sancionador por infracción al artículo 72.3 de la Ley de Tráfico. Pero nada impide tampoco que ese incumplimiento del deber de identificación, tanto si es evidente o burdo, como si trata de disfrazarse de forma más sutil, pueda ser valorado también en contra del propietario y, en consecuencia, aunque no puede sustituir la ausencia de prueba de cargo, so pena de asumir el riesgo de invertir la carga de la prueba, sí puede servir como contraindicio o como elemento de corroboración de los indicios a partir de los que es posible inferir la culpabilidad" (STC 63/2007, de 27 de marzo).

Así, no se consideró cumplida la obligación de identificar al conductor en el caso en el que se señaló como conductor a un ciudadano extranjero, señalando su domicilio en el extranjero con errores gramaticales a la hora de escribir la dirección, tras el intento de notificación por la Administración con resultado "desconocido" (Sentencia del TSJ País Vasco de 18 de octubre de 2002. Tampoco manifestar que el vehículo se pone a disposición de toda la familia, todos los días y a todas horas (TSJ Andalucía de 8 de junio de 2002).

* La doctrina jurisprudencial ha marcado las sucesivas reformas acometidas en el precepto cuestionado. Así, tras la modificación llevada a cabo por la Ley 19/2001, de 19 de diciembre se introdujo un nuevo apartado en el precepto al señalar: "En los mismos términos responderá el titular del vehículo cuando no sea posible notificar la denuncia al conductor que aquél identifique, por causa imputable a dicho titular".

Posteriormente, Ley 62/2003 de 30 de diciembre introduce una nueva obligación para las empresas de alquiler sin conductor al establecer que "acreditarán el cumplimiento de la obligación legal de identificar al conductor responsable de la infracción mediante la remisión, al órgano instructor correspondiente, de un duplicado o copia del contrato de arrendamiento donde quede acreditado el concepto de conductor de la persona que figure en el contrato".

Finalmente destaca por novedosa la llevada a cabo por Ley 18/2009, de 23 de noviembre. Así, la Ley de Tráfico en su reciente modificación aborda nuevamente la 
configuración del sistema de responsabilidad en los supuestos en que la identificación no puede producirse en el acto de la comisión del hecho infractor.

En este sentido, y con independencia de la figura de arrendatario, introduce un nuevo concepto el de "conductor habitual" definiéndolo en el artículo 1 bis del Anexo I de la nueva regulación como "la persona que, contando con el permiso o licencia de conducción necesario, que estará inscrito en el Registro de Conductores e Infractores, ha sido designada por el titular de un vehículo, previo su consentimiento, en virtud de lo dispuesto en el artículo 9 bis, por ser aquella que de manera usual o con mayor frecuencia conduce dicho vehículo".

La Ley permite al titular comunicar al Registro de Vehículos el conductor habitual, produciéndose un desplazamiento de la responsabilidad en el mismo en atención a la disponibilidad continuada sobre el vehículo. Si bien, no concreta la modificación, que deja a un posterior desarrollo reglamentario mediante Orden del Ministro del Interior, la forma en la que se ha de obtener el consentimiento para incluir la figura de un conductor habitual en el Registro de vehículos. Asimismo, aumentan considerablemente los deberes del titular del vehículo. En este sentido, si el conductor no figura inscrito en el Registro de Conductores e Infractores, se imponer al titular la obligación de disponer y facilitar a la Administración, previo requerimiento copia de la autorización administrativa que le habilite a conducir en España y de otro lado acreditar el consentimiento de éste.

Son varios los problemas que pueden surgir en la aplicación práctica de la norma, así en el caso de la negativa por parte del conductor a facilitar sus datos de carácter personal, una posible defectuosa comunicación de datos, la cesión de los mismos por su parte a la Administración requirente y la posibilidad de acceso al registro de conductores por parte de terceros interesados lo que obligará a extremar las medidas en aras al principio de seguridad que inspira la regulación de la protección de datos de carácter personal, para evitar el acceso a los datos por quienes no están autorizados, entre otras cuestiones.

Otro de los aspectos significativos de la reforma es el relativo a las consecuencia sancionadoras, ya que la Ley tipifica la infracción como muy grave con multa de 500 euros (artículo 67) para añadir a continuación que sin perjuicio de lo anterior, en la imposición de sanciones deberá tenerse en cuenta que la multa por la infringir el deber de identificación será el doble de la prevista para la infracción originaria que la motivó, si es infracción leve, y el triple, si es infracción grave o muy grave.

Esta agravación de la sanción, se podría entender como la manera de evitar las situaciones en la que el propietario-conductor, conocedor de que la infracción de tráfico está sancionada más gravemente que la prevista en el caso de falta de identifica338 ción, opta por no contestar al requerimiento administrativo. 
Se evita de esta manera el riesgo de que el deber de identificación se convierta en una prerrogativa del titular del vehículo, confiriéndole una auténtica opción para seleccionar el tipo infractor que más le conviene en caso en función de las distintas consecuencias sancionadoras.

Por último la Ley concreta los datos que han de ser facilitados a la administración para realizar la identificación, al exigir "el número del permiso o licencia de conducción que permita la identificación en el Registro de Conductores e Infractores".

En definitiva, con la nueva modificación aumentan notablemente los deberes de colaboración a cargo del titular del vehículo, cuya redacción ocasionará no pocos problemas interpretativos, que habrán de resolverse a la luz de la doctrina constitucional.

Recibido: 20 de noviembre de 2010

Aceptado: 10 de enero de 2011 
